\title{
JAK Kinases in Health and Disease: An Update
}

\author{
Arian Laurence ${ }^{1}$, Marko Pesu ${ }^{2,3}$, Olli Silvennoinen ${ }^{2,3}$ and John O’Shea ${ }^{*}, 1$ \\ ${ }^{I}$ Molecular Immunology and Inflammation Branch, National Institute of Arthritis and Musculoskeletal and Skin \\ Diseases, National Institutes of Health, Bethesda, Maryland 20892, USA \\ ${ }^{2}$ Institute of Biomedical Technology, FI-33014 University of Tampere, Finland \\ ${ }^{3}$ Centre for Laboratory Medicine, FI-33520 Tampere University Hospital, Finland
}

\begin{abstract}
Abstact: Janus kinases (Jaks) are critical signaling elements for a large subset of cytokines. As a consequence they play pivotal roles in the patho-physiology of many diseases including neoplastic and autoimmune diseases. Small molecule Jak inhibitors as therapeutic agents have become a reality and the palette of such inhibitors will likely expand. This review will summarize our current knowledge on these key enzymes and their associated pharmaceutical inhibitors.
\end{abstract}

Keywords: Jak, tyrosine kinase, kinase inhibitors, autoimunity, myelofibrosis, cancer, cytokine signaling.

\section{INTRODUCTION}

Cytokines are hydrophilic glycoprotein hormones, which act both locally and systemically and are essential for development, homeostasis and host defense. Due to their hydrophilic nature cytokines cannot penetrate through the lipid containing cell membrane; instead cytokines function through binding to a cognate receptor proteins, which trigger phosphorylation and activation of intracellular signaling proteins. Growth factor cytokine receptors typically have intrinsic kinase activity. The binding of a growth factor brings the multiple monomeric receptor chains into close proximity resulting into the trans-phosphorylation of their cytoplamic domains, which consequently activates downstream signaling cascades. In contrast, classical immune (type I/ II) cytokine receptors do not have intrinsic protein kinase activity but associate with the Janus family of kinases (JAKs). The JAKs, which include TYK2, JAK1, JAK2, and JAK3, were initially identified using PCR-based strategies and low-stringency hybridization $[1,2]$. Despite the roughly 60 type I/II cytokines discovered, there are only four members in the JAK kinase family. Since the sequencing of other vertebrate genomes has been completed, we also know now that there are indeed only four JAKs in mammals, birds and fish. In D. melanogaster there is only one JAK member (hopscotch).

The identification of the STAT family of transcription factors (STAT1-5a, 5b and 6) was complementary to the discovery of JAK's [3]. Formation of the cytokine receptor / JAK signaling complex and activation of JAK kinases leads to the phosphorylation of receptor chains, which creates docking sites for STAT (Signal Transducers and Activators of Transcription) transcription factors. Upon cytokine activation receptor chain- bound STATs are then

*Address correspondence to this author at the Molecular Immunology and Inflammation Branch, National Institute of Arthritis and Musculoskeletal and Skin Diseases, National Institutes of Health, Bethesda, Maryland 20892, USA; Tel: +1 301-496-2612; Fax: +1 301-480-6372;

E-mail: osheajo@mail.nih.gov phosphorylated on the tyrosine residues, which results in dimerisation of STAT proteins that translocate to the nucleus and activate gene transcription. In addition to the tyrosine phosphorylation, phosphorylation of threonine and serine residues has been demonstrated. These additional phosphorylation events are currently incompletely understood but it has been suggested to have implications in the modulation of the STAT transcriptional activity and perhaps also target gene specificity [4]. Importantly, STATs are able to both induce and repress gene transcription $[5,6]$.

Although JAK's and STAT's are functionally linked, JAK's have substrates and activate other signaling pathways [7]. This critical requirement for JAK's in regulating the actions of type I/II cytokine receptors is reflected in the importance of JAK proteins in the patho-physiology of a number of cytokine dependent inflammatory and immune disorders. The genetic association of JAK mutations with a plethora of diseases including immunodeficiencies, myeloproliferative disorders and cancers has highlighted the importance of these proteins in relaying cell survival and proliferative messages. Consequently, a number of pharmaceutical inhibitors of JAK's are poised to enter common clinical use in the therapy for a variety of immune and neoplastic diseases. In addition, an activating mutation in the pseudokinase domain of JAK2 (V617F) is routinely screened to diagnose myeloproliferative disorders, especially primary polycythemia [8-10].

\section{STRUCTURE OF JAK PROTEINS}

The seven regions of sequence similarity found between JAK kinases have been noted and designated Janus homology (JH1-7) domains (Fig. 1). Based on similarity to other motifs however, it is more feasible to divide JAKs into FERM (a band four point one, ezrin, radixin, moesin), SH2, pseudokinase and Kinase domains. Mutations in any of these domains can lead to functional changes in the activity of JAK-STAT pathway (gain or loss-of function). Despite intensive efforts by many laboratories the crystal structure of a complete JAK molecule has yet to be solved, which has certainly limited our understanding on the structure- 


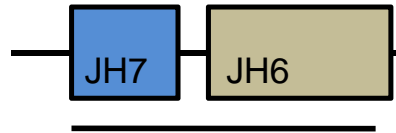

FERM domain

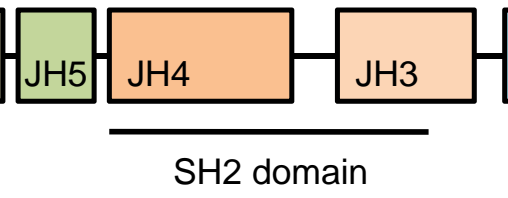

$\mathrm{SH} 2$ domain

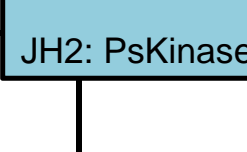

V617F

Fig. (1). Domain structure of JAK protein family members. JH: Jak homology domains: functional regions are highlighted and include a FERM (Band4.1 ezrin radixin moesin) domain that mediates cytokine receptor binding, an SH2 (Src homology 2) domain and two kinase domains of which only the second is functional. The V617F mutation found in JAK2 is lies within the enzymatically inactive pseudo kinase domain.

functional roles of aforementioned domains. However, recently Garcia and colleagues used electron microscopy imaging which gave "structural snapshots" of full-length JAK1 [11]. Their 2D and 3D reconstructions revealed a three lobed structure comprising FERM-SH2, pseudokinase, and kinase domains, which had significant inter-segmental flexibility that can contribute to allosteric activation.

Mutational analysis has indicated that the amino-terminal FERM domain in JAKs is the major mode through which JAKs bind the membrane proximal domain of cytokine receptors [12]. In addition, interfering with the structural integrity of FERM domain results in dysregulation of catalytic activity and auto-inhibition of JAK1 [13].

The carboxy-terminal catalytic (kinase) domain of several JAKs has been solved using crystallography (Fig. 2). The structure of the isolated JAK3 kinase domain was first crystallized in complex with a staurospsorine analog [14]. This study has been confirmed by others all of which have used a similar strategy; elucidating the structure of the kinase domain held in complex with an inhibitor [15-17]. These studies are important for the design of future JAK inhibitors and add to our understanding the especially on the ATP binding determinants of the JAK kinase domains. Like the catalytic domains of other typical protein kinases, the JAK kinase domain consists of two lobes (N-lobe and C-lobe) that surround the ATP binding site. The kinase domain contains a characteristic gate-keeper residue that is exploited to generate relatively specific inhibitors of individual JAK family members [18].

Like other protein tyrosine kinases, JAK have an "activation loop" which in all JAKs consists of tandem tyrosine residues. The loop region regulates kinase activity and is a major site of autophosphorylation. Perhaps due to its critical role in EPOR signaling and consequently erythropoiesis [19] JAK2 has been the subject to most thorough phospho amino acid analysis and approximately 20 tyrosine residues have been identified to be phosphorylated upon cytokine stimulation. Several of these sites have been functionally characterized and in addition to activation loop Y1007/1008, phosphorylation of Y637, Y813, Y868, Y966 and Y972 have been shown to potentiate JAK2 activity, while phosphorylation of Y119, Y221, Y317, Y570 and Y913 regulate JAK2 activity negatively [20-22]. Interestingly, in the absence of cytokine stimulation, JAK2 is constitutively phosphorylated on a single residue, S523, which mediates negative regulation of JAK2 activation [23, 24]. The precise mechanisms how these phosphorylation events regulate JAK activity is only known for a few residues. For example, phosphorylation of Y119 in the
JAK2's FERM domain required for JAK2 to associate with the erythropoietin receptor and mediate enhanced erythropoesis.

JAK proteins are named after the two-headed Roman god Janus indicative of the presence of two kinase domains within these proteins. The second kinase domain is catalytically inactive and lies immediately N-terminal to the active kinase domain (Fig. 1). The pseudokinase domain has a high degree of sequence similarity to the kinase domain, but several residues required for phosphotransferase activity are altered from the canonical motifs. Though the pseudokinase domain itself lacks catalytic activity, this domain has critical functions in regulating enzymatic activity of the active domain [25-27]. The importance of the pseudokinase domain is most vividly illustrated in gain-offunction mutants in this domain. First recognized as the tumorous lethal (tuml) mutation in the Drosophila JAK [28], hopscotch; it is now recognized that mutations in the pseudokinase domain of JAK2 are responsible for nearly all cases of primary polycythemia (discussed later). Recently, activating mutations have also been discovered in the SH2pseudokinase domain linker region [29],

\section{TYK2: FUNCTION IN KO MICE, ROLE IN DISEASE}

TYK2 (TYrosine Kinase 2) was the first member of the JAK family to be discovered from lymphocyte cDNA libraries using low stringency probe for FMS tyrosine kinase [2]. Its importance has been elucidated in part by the development of targeted germline TYK2 deficiency [25] and by the discovery of a single patient with a TYK2 mutation [30] (Table 1). TYK2 associates with a large number of cytokine receptors that include members of the interfearon (IFN) and IL-10 receptor families, the IL-6 family and the IL-12/23/27 group (Fig. 3).

Because the TYK2 deficiency interferes with several cytokine receptors, many of which have either complimentary or opposing biological effects, the interpretation of mice and humans with impaired TYK2 function is difficult. For example, TYK2 deficiency leads to compromised IFN- $\alpha / \beta$ and IFN- $\gamma$ signaling, which are generally associated with susceptibility to viral infections and inadequate cell-mediated immune responses against intra-cellular pathogens, such as mycobacteria. In addition, IL-12, a cytokine that is critical for generating IFN- $\gamma$ secreting T helper 1 (Th1) cells, utilizes TYK2 in its signal transduction [31]. Activation of the IL-12R or IFN- $\gamma \mathrm{R}$ signaling complexes leads to STAT4 and STAT1 phosphorylation respectively. STAT4 and STAT1 in conjunction with signals from the $\mathrm{T}$ cell receptor induces the expression of $\mathrm{T}$-bet, the master transcriptional regulator of 


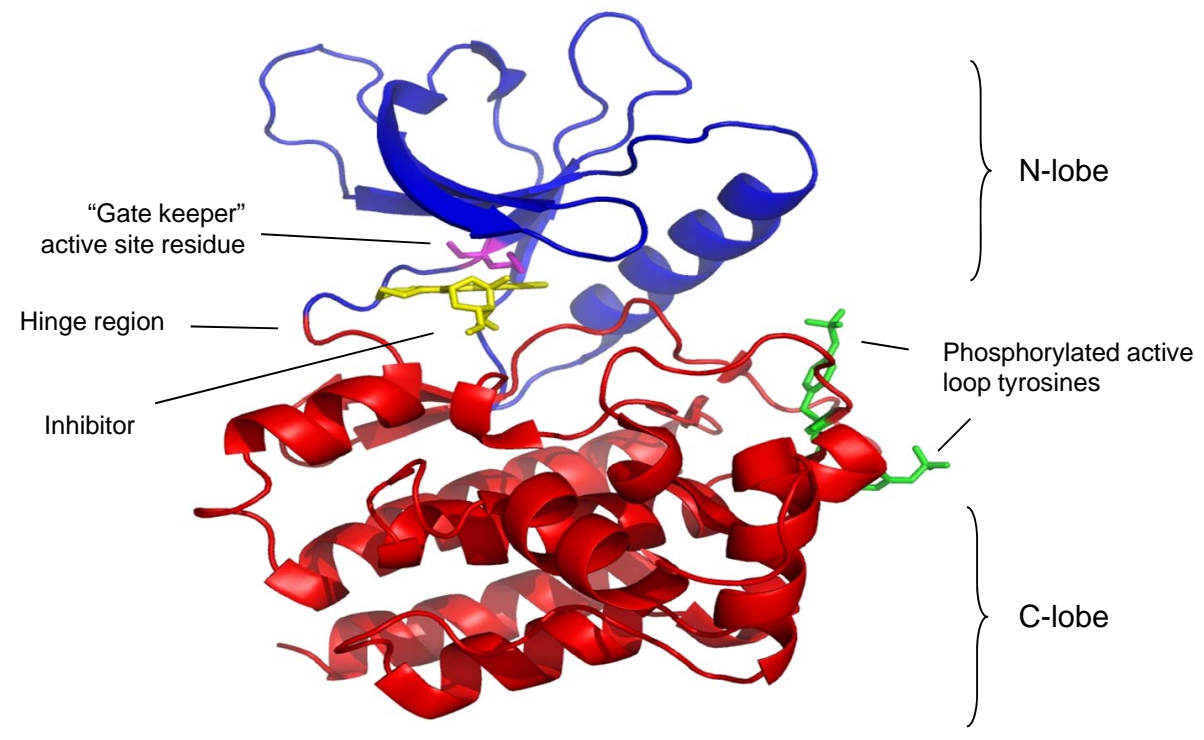

Fig. (2). Crystal structure of the Jak3 kinase domain in complex with staurosporine (pdb accession code 1YVJ). This structure captures the active conformation of Jak3 with both active loop tyrosine residues phosphorylated (green). The molecule can be described in two halves, with the $\mathrm{N}$ terminal lobe presented in blue and the $\mathrm{C}$ terminal domain in red. These are linked by a hinge region that forms part of the active site. Highlighted in magenta within the active site is the gate keeper residue. Bound within this site is an analogue of the inhibitor staurosporine, and its proximity to the "gate keeper" residue highlights why this residue and this region are critical for the specificity of inhibitors for individual protein kinases.

Th1 cells [31], and inhibits the generation of IL-4 secreting Th2 cells that are associated with anti-helminth immunity and the development of atopic diseases including asthma. Consistent with these predictions, generation of TYK2 gene targeted mice revealed that these animals had poor anti viral immunity [25]. However, the impairment was less dramatic than that expected, as type I IFN (IFN- $\alpha / \beta)$ signaling was reduced but not abolished. Conversely, these mice had enhanced Th2 responses with heightened allergic lung inflammation characterized by an eosinophilia and elevated $\operatorname{IgE}$ levels [32].

In addition to IL-12, TYK2 is required for IL-23 and IL27 receptor signaling. IL-23 receptor is expressed on myeloid cells and innate and adaptive lymphocytes. Mice deficient for IL-23 are resistant to a wide variety of autoimmune diseases [33-35], conversely these animals are deficient in IL-22 and IL-17 production, both of which are required for defense against extra cellular bacterial and fungal infections $[36,37]$. In humans genetic susceptibility loci for inflammatory bowl disease have been associated with genes encoding the components of the IL-23 receptor and its downstream signaling proteins, TYK2 and STAT3 [38]. This has resulted in a renewed interest in designing TYK2 inhibitors.

A single patient with autosomal recessive hyperimmunoglobulin E (AR-HIES) has been described with mutations of TYK2 [30, 39]. This patient suffered from multiple opportunistic infections. In contrast to what was reported in the mouse, signaling by a wide variety of cytokines including Type I IFNs, IL-6, IL-10, IL-12, and IL23 was found to be impaired. Thus, the requirement for TYK2 for various cytokines remains somewhat unclear and probably reflects cell- and possibly species-specific effects.

\section{JAK1: FUNCTION IN KO MICE, ROLE IN DISEASE}

Whereas defects in TYK2 signaling has been reported in a patient and explored in adult mice lacking the kinase, individuals with a deficiency in JAK1 have not been described. This is in accordance with the perinatal lethal phenotype of mice that lack JAK1 [40]. JAK1-deficient

Table 1. Effect of Mutations in Jak Family Genes in Humans and Mice

\begin{tabular}{|l|l|l|}
\hline & \multicolumn{1}{|c|}{ Deficiency in Mice } & \multicolumn{1}{c|}{ Deficiency in Humans } \\
\hline \hline TYK2 & $\begin{array}{l}\text { Impaired anti-viral, anti-fungal and anti-bacterial } \\
\text { immunity, enhanced lung inflammation }\end{array}$ & Autosomal recessive hyper-immunoglobulin E \\
\hline JAK1 & $\begin{array}{l}\text { Perinatally lethal with major deficits in nerve } \\
\text { development and lymphopoesis }\end{array}$ & $\begin{array}{l}\text { Deficiency not reported. } \\
\text { Acquired gain of function mutations associated with acute leukemia. }\end{array}$ \\
\hline JAK2 & Embryonically lethal due to defective erythropoesis & $\begin{array}{l}\text { Deficiency not reported. } \\
\text { Germline gain of function mutations associated with inherited polycythaemia, acquired } \\
\text { mutations associated with myeloproliferative disease and acute leukemia. }\end{array}$ \\
\hline JAK3 & $\begin{array}{l}\text { Severe combined immunodeficiency with lack of T, } \\
\text { B and NK cells }\end{array}$ & $\begin{array}{l}\text { Severe combined immunodeficiency with lack of T and NK lymphocytes. } \\
\text { Acquired gain of function mutations associated with acute leukemia }\end{array}$ \\
\hline
\end{tabular}




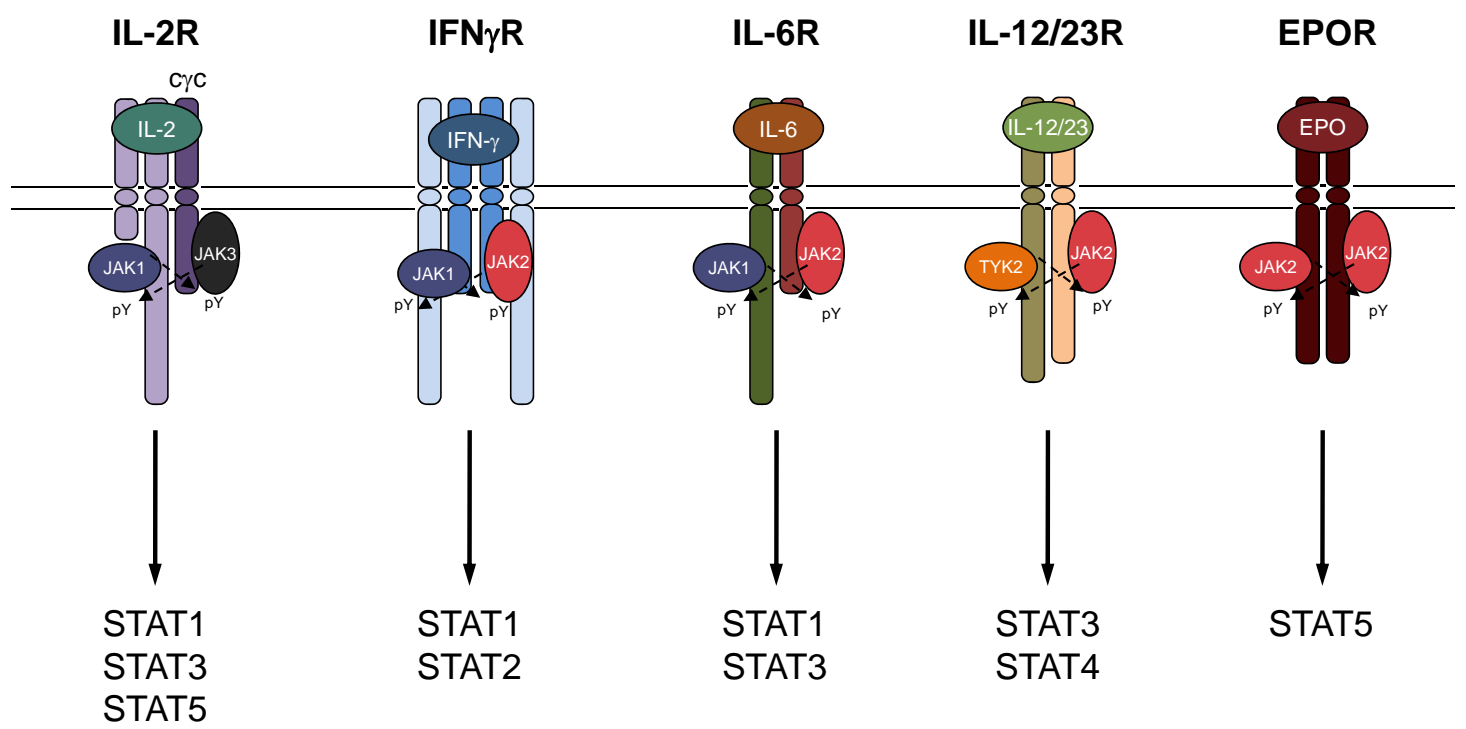

Fig. (3). JAK family members associate with Type I/II cytokine receptor subunits.

mouse embryos have major deficits in nerve development and lymphopoiesis. JAK1 associates with cytokine receptors of the common gamma chain cytokine family, the gp130 family that includes IL-6 and members of the IFN family (Fig. 3).

In vitro studies have identified an essential role for JAK1 in IFN receptor signaling with JAK1 pairing with either TYK2 to mediate type I IFN (IFN- $\alpha / \beta)$ responses or JAK2 to mediate type II (IFN- $\gamma$ ) responses. In both cases the requirement for JAK1 was essential but that there is a degree of redundancy between TYK2 and JAK2. Since no upstream or downstream regulation has been described, the combined activation of the JAK family members seems to occur at the same level within the receptor complex [41]. In cytokines of the IL-2 receptor common gamma chain family (c $\gamma \mathrm{c})$ JAK1 universally associates with JAK3 and again there is some evidence to suggest a greater role for JAK1 in downstream signaling (Fig. 3). For example, some of the functions of IL7 can be performed by the related cytokine Thymic stromal lymphopoietin (TSLP), which shares the IL-7R alpha chain but also has its own unique receptor subunit that associates with JAK2. Nevertheless, TSLP is able to activate the same downstream signaling pathways as IL-7 [42]. Furthermore, Haan and colleagues compared the actions of JAK1 and JAK3 inhibitors on the ability of c $\gamma \mathrm{c}$ cytokines to activate STAT5 and found a more profound effect when JAK1 was blocked compared with JAK3. They concluded that the principal target of JAK3 was the phosphorylation of JAK1 where as the principal target of JAK1 was STAT5 [43]. Although these conclusions are contingent on the selectivity of the inhibitors used.

JAK1 has been associated with a number of acute leukemias although the subject is controversial. The M3 subtype of acute myeloid leukemia, known as acute promyelocytic leukemia (APML) is associated with a chromosomal translocation of chromosomes 15 and 17 to generate the PML-RARA fusion protein, a mutant transcription factor that requires the presence of high doses of all trans retinoic acid (ATRA) to bind to DNA and facilitate the differentiation of leukemic promyelocytes to form neutrophils. Mice that constitutively express the PMLRARA gene have a delayed development of APML. The development of APML in these animals is often associated with active mutations of JAK1 and the addition of an active JAK1 rapidly induces APML in these animals [44]. In acute lymphoblastic leukaemia groups have reported both the presence of JAK1 mutations [45, 46] and their rarity [47]. This may be due to both the proliferative potential of STAT5 signaling downstream of JAK1 and the anti-proliferative potential of STAT1 signaling, supporting the later, ALL clones with active JAK1 seem to be sensitive to the effect of inhibition by type I IFN's [48].

\section{JAK2: FUNCTION IN KO MICE, ROLE IN DISEASE}

JAK2 deficiency, like JAK1, is lethal in mice: animals with a targeted gene deletion of JAK2 die in utero at embryonic date 12.5 due to defective erythropoiesis. Activation of the Epo receptor induces tyrosine phosphorylation of JAK2, required for the biological activity of Epo [49]. Although primitive erythrocytes are found in JAK2-deleted mice, the number of c-kit Ter $119^{+}$erythroblast cells is dramatically reduced, resulting in the absence of definitive erythropoiesis. In keeping with this, no JAK2 deficient patients have been described although patients that acquire mutations that lead to heightened JAK2 activity are surprisingly common.

JAK2 associates with both the Epo and TSLP receptors, activation of which is important to maintain erythoid and B cell development and proliferation, in keeping with this, activating mutations of JAK2 have been associated with neoplasia of both of these two lineages. In 2005, a number of independent groups using different reasoning and approaches (JAK2 as a candidate gene based on of its function, "Loss of Heterozygosity" in the JAK2 region, JAK2 siRNA on EEC formation, high-throughput DNA sequencing of kinase domains) identified the importance of JAK2 in Myeloproliferative disease (MPD) [50-53]. MPDs are haematologic neoplasias that are characterized by excess proliferation of one or more myeloid lineages. In contrast to 
acute myeloid leukemia (AML), the excess cells are differentiated and functional, and unless the disease progresses into a frank acute leukaemic state most patients can be managed symptomatically. The principal MPD's include primary polycythemia (PPV), primary thrombocythaemia (ET), primary myelofibrosis (PMF), and chronic myeloid leukemia (CML).

CML was the first cancer to be linked to a specific oncogene: BCR-Abl, in most cases caused by a reciprocal translocation of chromosomes 9 and 22 [54]. CML was also a groundbreaking disease in the drug development, first targeted tyrosine kinase inhibitor (imanitib) was tailored to inhibit the culprit kinase (imanitib) [55]. The finding that imatinib could block CML progressing into acute leukaemia was critical to its success. In contrast to CML, the other three major forms of MPD have no association with Abl kinase activation, but all three are related by an association with mutations in JAK2, most commonly a V617F point mutation that results in a constitutively active kinase [29] (Fig. 1). The V617F mutation lies within the previously characterized autoinhibitory region in the pseudokinase domain of JAK2 [27]. Understanding the precise manner through which $\mathrm{V} 617 \mathrm{~F}$ results in the dysregulation of JAK2 activity will require solution of the complete crystal structure of JAK2. However, it is plausible to propose that V617F disrupts the interaction between the kinase and pseudokinase domain, which is needed to keep JAKs in inactivate state; this then results in the spontaneous autophosphorylation and activation of the mutated kinase, rendering transfected hematopoietic cells independent of cytokines for growth and survival [50, 53]. Furthermore, the V617F mutation may render the JAK2 protein resistant to the effect of SOCS3 binding allowing it to escape a second regulatory constraint [56]. JAK2 V617F has been identified in $95 \%$ of patients with PPV and over $50 \%$ of patients with ET and PMF [50-53]. The very high incidence of $J A K 2 V 617 F$ in PPV may result in the disease becoming defined by the oncogenic mutation, much as Abl kinase mutations define CML, with the rare cases of BCR-Abl negative CML renamed as atypical-CML.

In addition to its relationship with MPD, number of fusion proteins comprising transcription factors and JAK2 have been recognized in other forms of hematological malignancy. Analogous to the activating JAK2 V617F mutation, these fusion proteins are also constitutively activated kinases. TEL-JAK2, which comprises the oligomerization domain of ETS family transcription, TEL (translocated ETS leukemia), linked to a truncated form of JAK2 [57]. The fusion event is responsible for constitutive activation of the JAK2 kinase. Mice that express TEL-JAK2 spontaneously develop a fatal leukemia, mediated by uncontrolled expansion of $\mathrm{CD}^{+} \mathrm{T}$ cells with activation of STAT1 and STAT5 downstream of the mutant kinase [58]. Insertion of TEL-JAK2 into human hematopoietic cells using a retrovirus led to Epo-independent STAT5 activation, erythroid differentiation in vitro, and myelofibrosis in vivo upon transplantation into non-obese diabetic (NOD)/SCID mice [59].

In addition to TEL-JAK2, other JAK2 fusion proteins have been noted in patients with atypical CML, including PCM1-JAK2 or BCR-JAK2 fusion proteins that similarly result in the generation of active kinases. Similarly, in the setting of acute leukemia, JAK2 fusion proteins have been reported [60-63]. The oncogenic potential of PTK fusion proteins is further underlined by translocations leading to TEL-PDGFR or TEL-Abl as observed in some patients with chronic myelomonocytic leukemia or acute lymphoblastic leukemia (ALL), respectively [64, 65]. Patients with Downs syndrome (DS, trisomy 21) have a predisposition to develop both AML and ALL, in the latter over a quarter of DS associated ALL have mutations in JAK proteins most commonly affecting the JAK2 pseudokinase domain at or around R683 [66-71].

The crucial role of active JAK2 in tumor cell transformation and proliferation was underlined by kinasetargeting strategies to inhibit JAK2 activity. The pro-B cell line $\mathrm{Ba} / \mathrm{F} 3$ is dependent on the presence of IL-3 to grow. Insertion of TEL-JAK2 is able to overcome this dependence and is associated with constitutive activation of STAT3 and STAT5 [72] This could be reversed by retroviral expression of SOCS1, a known inhibitor of JAK2 signaling, in the TELJAK2 transformed Ba/F3 cells. Silencing JAK2 activation by ectopic expression of SOCS1 inhibited cell proliferation and survival in vitro. Consistent with this, the insertion of SOCS1 prevents TEL-JAK2-driven neoplasic disease when the transformed cells are transplanted into immunocompromised mice [73]. Intriguingly, the mutation-based constitutive activation of JAK can still be controlled by induced expression of specific JAK signaling inhibitors such as SOCS1 or by kinase inhibitors that are currently used in clinical trials $[74,75]$. The success of the Abl kinase inhibitor, imatinib, in CML, suggests that JAK2 inhibitors are likely to generate effective therapies for the treatment of myeloproliferative disease.

JAK proteins have traditionally thought to relay their effects exclusively by virtue of downstream signaling pathways that include the STAT proteins. Recently, work by Kouzarides and colleagues has questioned this, they identified that JAK2 could localize to the cell nucleus and directly phosphorylate the Y41 position of Histone H3, this leads to a genome wide alteration in $\mathrm{H} 3$ methylation and the enhanced transcription of a number of oncogenes that include $M y c$ and $l m o 2$ [76]. In a third of cases of Hodgkin lymphoma JAK2 activity is indirectly enhanced by a mixture of gene duplication and deletion of the JAK2 inhibitor SOCS1, the presence of elevated active JAK2 is associated with a genome wide decrease in $\mathrm{H} 3 \mathrm{~K} 9$ methylation and a positive feedback of elevated Myc, JAK2 and IL-4 expression that in turn leads further activation of JAK2 [77].

\section{JAK3: FUNCTION IN KO MICE, ROLE IN DISEASE}

In contrast with the other three JAK members that are able to associate with multiple ubiquitously expressed cytokine receptors, JAK3 only associates with a single receptor chain that is only expressed within cells of the haematopoetic system. This receptor chain is the IL-2 c $\gamma \mathrm{c}$. The cyc pairs with other ligand-specific subunits to form the receptors for interleukin (IL)-2, IL-4, IL-7, IL-9, IL-15 and IL-21 [78]. Germline deletion of the $\mathrm{c} \gamma \mathrm{c}$ in mice or mutations of the chain in humans (denoted IL2RG) results in a severe combined immunodeficiency (SCID) characterized by the lack of lymphocytes in mice and the absence of $\mathrm{T}$ cells and NK cells but not $B$ cells in humans [79]. A similar 
phenotype is seen with loss of JAK3 in both humans and mice [80], and combined, mutations of IL2RG /JAK3 account for the majority of all cases of T(-)NK(-)B(+)SCID. While it is clear that mutations of JAK3 have profound effects on the immune system, it is also equally clear that these patients do not have other deficits. Moreover, hematopoietic stem cell transplants are curative for both conditions, arguing for very discrete functions of JAK3. Activation of cyc receptor complexes results in the recruitment of JAK3 that in turn phosphorylates STAT5A and STAT5B. STAT5s are widely expressed, but mice that lack both STAT5 genes within their $\mathrm{T}$ cells have a remarkably similar phenotype to germline JAK3 and $c \gamma c$ knockouts, a finding that highlights their close functional relationship in immune cells [81].

The phenotype of mice with either c $\gamma \mathrm{c}$ or JAK3 deficiency can be attributed to many of the individual members of the c $\gamma \mathrm{c}$ cytokine receptor family. In terms of the SCID phenotype, inhibition of IL-7 receptor explains many of the abnormalities associated with deficiency of $c \gamma c$ and JAK3. In mice, IL-7R deficiency disrupts thymocyte development at the double negative (CD4-CD8-) stage prior to productive $\mathrm{T}$ cell receptor rearrangement, which results in marked reduction in thymocytes and peripheral $\mathrm{T}$ cells, including $\gamma \delta \mathrm{T}$ cells. Furthermore, mutations of $I L 7 R$ underlie about $10 \%$ of autosomal recessive SCID patients. In the mouse, the IL-7R is also critical for B cell development, in part due to its role in regulating the transcription factor Pax-5 [82]. However, B cells are present in patients with $J A K 3$, IL2RG, and $I L 7 R$ mutations, indicating that IL-7/IL$7 \mathrm{R}$ is dispensable for human $\mathrm{B}$ cell development [83]. In contrast with thymocytes and naïve peripheral $\mathrm{T}$ cells that are dependent on IL-7, NK cells are dependent on a second c $\gamma$ c cytokine, IL-15. In other words defective expression of IL-7R in humans results in a SCID phenotype where only the $\mathrm{T}$ cell compartment is affected; $\mathrm{T}(-) \mathrm{NK}(+) \mathrm{B}(+)$ [83], this is probably because the signaling components essential for maintenance of the NK cell pool (IL-15R, IL-2R $\gamma$ ) are intact in these individuals.

IL-2 is the prototypic T cell growth factor, and although it was expected this cytokine would be essential for development and function of $\mathrm{T}$ cells, this is not the case. In fact, mice lacking either IL-2 or IL-2R (IL-2R $\alpha$ and $\beta$ ) are normal with respect to thymus development and peripheral $\mathrm{T}$ cell subset composition [84-86], but surprisingly, die of a systemic inflammatory disease that is characterized by wide spread $\mathrm{T}$ cell lymphoproliferation, colitis and anemia depending on the mouse strain. There are multiple explanations for this paradox but chief among them is the identification of regulatory $\mathrm{T}$ cells (Tregs) that are characterized by expression of the IL-2R $\alpha$ (or CD25) and the transcription factor FoxP3 [87]. Treg cells are required to suppress immune cell activation and their deficiency is associated with a rapidly fatal inflammatory disease in both mice and humans. Consistent with this, patients with mutations in the IL-2R $\alpha$ subunit have extensive lymphocytic infiltration and inflammation $[88,89]$. In addition to its role in promoting Treg cell development and survival, IL-2 is able to inhibit the generation of inflammatory IL-17 expressing Th17 cells that have been associated with a number of inflammatory diseases in both mice and humans. Th17 cells [90, 91], like Treg cells can be induced by their activation in the presence of TGF- $\beta$ [92, 93]. The combination of TGF- $\beta$ with STAT5 activation, downstream of IL-2 and JAK3 leads to Treg development $[94,95]$ where as the combination of TGF- $\beta$ with STAT3 activation leads to Th17 development [91, 96-98]. Mice that lack both STAT3 and IL-2 have deficient Treg and Th17 cell development and have a prolonged survival compared with IL-2 deficient animals [5].

In principle, lack of IL-2 signaling in JAK3-SCID patients and $J A K 3^{-/}$mice should result in autoimmunity. $J A K 3^{-/-}$mice are born lymphopenic but with time these mice accumulate activated $\mathrm{T}$ cells that can lead to a similar presentation to IL-2 deficient animals, albeit at a later age. Consistent with this, not all patients with IL2RG and JAK3 mutations have profound lymphopenia [99-102]. If $\mathrm{T}$ cells are generated, it is possible that autoimmune manifestations can occur and a JAK3-deficient patient with a mixed picture of immunodeficiency and autoimmunity has been identified.

The last c $\gamma \mathrm{c}$ cytokine to be discovered, IL-21 is unusual for the family in that it principally signals through STAT3. Unlike the other family members it is able to induce Th17 and $\mathrm{T}$ follicular cell development in $\mathrm{T}$ cells and the maturation of B cells [103].

The clear genetic evidence in mouse and man implies that JAK3 is only essential and non-redundant with respect to its role in the immune response. This apparent specificity of JAK3 function in the immune system has important implications for the development of a new class of immunosuppressive drugs that will be discussed later. Despite the unequivocal genetic evidence, it is possible that JAK3 is expressed in cells other immune cells - indeed databases that catalogue gene expression suggest that JAK3 can be expressed in non-hematopoietic cells. Nonetheless, JAK3-deficient SCID patients and $J A K 3^{-/-}$mice indicate that this kinase does not have essential roles outside hematopoietic cells.

SCIDs due to mutations of $J A K 3$ or IL2RG are lifethreatening disorders. The hematopoietic stem cell transplant is currently the treatment of choice for JAK3-SCID. Optimal results (up to $95 \%$ survival rate) have been obtained with bone marrow transplantation from human leukocyte antigen (HLA)-matched siblings, whereas the survival rate is lower when HLA-mismatched family donors are used. HSCT treatment is not always feasible, patients may develop graft versus-host disease or a suitable donor may not be available. Therefore much experimental work has been aimed at developing alternative gene therapy approaches for treatment of $J A K 3 / I L 2 R G$ SCID patients. Clinical trials using gene therapy to reconstitute $\mathrm{c} \gamma \mathrm{c}$ expression in X-SCID were initiated in 1999 in France. Ten classical X-SCID patients received autologous $\mathrm{CD} 34^{+}$stem cells transduced with a replication-defective retroviral vector containing the $I L 2 R G$ transgene without prior myeloablation. The efficacy of gene therapy was satisfactory- normal numbers of circulating $\mathrm{T}$ and NK cells were eventually reached in most patients [104]. Unfortunately, three years after the treatment two of the treated SCID patients started developing a leukemic-like process with expanded clonal populations of $\mathrm{T}$ cells, since then four of the ten patients have developed leukemia [105]. It is unclear whether the leukemias were due to aberant insertion of the IL2RG gene or whether IL2RG gene is 
directly leukemogenic, evidence supporting the latter is the ability of both $\mathrm{c} \gamma \mathrm{c}$ and JAK3 signaling to induce STAT5 expression, a potent proliferative and pro-survival factor, the ability of $I L 2 R G$ retroviruses to directly induce leukemia in mice [106], and finally the absence of cases of leukemia in adenosine deaminse deficiency induced SCID rescued with retroviral gene therapy. Many of the T cell leukemia's were associated with aberrant $L M O 2$ expression and in both of the initial leukemia sufferers there was evidence of retroviral $I L 2 R G$ insertion close to the $L M O 2$ gene with the retroviral enhancer elements inducing aberrant expression of the oncogene [105]. However, it is known that elevated JAK2 expression can directly open the $L M O 2$ locus by direct histone $\mathrm{H} 3$ phosphorylation [76], a property that could be shared by other JAK family members. To this end a new generation of retroviral vectors have been designed that lack enhancer elements and use weak cellular promoters of $I L 2 R G$ expression, it remains to be seen whether such promoters are both safe and efficacious [107].

At least $70 \%$ of patients with AML show evidence of STAT5 activation within the leukemic blast cells [108]. In view of the close relationship between JAK3 and the proproliferative, pro-survival STAT5 signaling pathway it would be surprising if JAK3 did not also have a role in the development of leukemia analogous to that seen with JAK1 and JAK2. JAK3 mutations have been associated with AML [109-111], ALL [69] and lymphomas [112, 113].

\section{NEGATIVE REGULATION OF JAKS: SOCS PROTEINS AND OTHER MECHANISMS}

Phosphorylation in the JAK activation loop allows one member of a family of negative regulators termed suppressors of cytokine signaling (SOCS), SOCS1, to bind and inhibit JAK activity. SOCS protein expression is induced by STAT activation so providing a negative feedback loop to regulate cytokine activity. Thus, the presence of one cytokine can lead to the expression of SOCS proteins that can both inhibit the activity of this initial cytokine and other, unrelated cytokine receptors. For example IFN- $\gamma$ activates STAT1 that in turn leads to SOCS1 expression. Deficiency of SOCS1, is associated with both elevated STAT1 activity and also enhanced signaling by $\mathrm{c} \gamma \mathrm{c}$ cytokines with elevated STAT5 activity [19, 40, 114]. In addition, all seven SOCS family members (CIS, SOCS1-6) are E3 ubiquitin ligases that can complex with elongins B and $\mathrm{C}$, Cullin-5 (Cul-5), and $\mathrm{Rbx} 1$ to mediate the ubiquitination of JAKs, and their subsequent degradation [115-117].

In addition to the SOCS proteins the adaptor protein, Lymphocyte linker (Lnk) protein has been demonstrated to inhibit JAK2 function. Lnk contains an SH2 domain that binds to phosphorylated tyrosine residues on JAK2 inhibiting its ability to activate downstream STAT proteins. Mice deficient in Lnk have elevated myeloid expansion with an associated myelofibrosis. These animals have a predisposition to develop myelo-proliferative disease [118, 119].

\section{NOVEL JAK SUBSTRATES}

When JAK proteins were first described there were more kinases known than protein substrates. The discovery of
STAT family members confirmed the traditional role of JAK proteins as proximal to cytokine receptor complexes upstream any associated signaling pathway. The recent discovery that JAK proteins can be found within the cell nucleus has led to an expansion in the number of protein substrates for these kinases. The single JAK found in drosophila, Hop, is known to phosphorylate the Drosophila STAT protein, STAT92E [120]. Activating mutations of Hop induce a leukaemia in Drosophila analogous to JAK2 mutations. Analogous to JAK2, the presence of active Hop is associated with changes to chromatin condensation and the activation of genes that show no direct evidence of being regulated by STAT92E. Subsequently JAK2 has been shown to directly phosphorylate Histone 3 that in turn leads to a reduction in chromatin condensation [76, 121]. While these findings remain controversial [122], it is possible that other JAK proteins share this function. In addition to the general effects on gene transcription, nuclear JAK2 is able to phosphorylate and degrade the cell cycle inhibitor p $27^{\text {Kip1 }}$ [123]. The increased interest in JAK's as oncogenes is likely to reveal novel properties for these kinases in the future.

\section{JAKS AS PHARMACOLOGICAL TARGETS}

The structural similarity between differing protein kinases initially cast doubt on the notion that therapeutically useful kinase inhibitors could be generated. As there are more than 500 human kinases, many of which serve critical cellular functions, would it really be possible to attain the specificity needed? Now some 20 years later with nine protein tyrosine kinase inhibitors approved by the Food and Drug Administration (FDA) and numerous more agents coming to market, these fears have been quashed. There are several reasons to explain this. First, protein kinases in their active ATP bound form are remarkably similar but in their inactive form the side chain of a single amino acid faces into the ATP binding pocket. This 'gate-keeper' residue is highly variable; almost any amino acid can appear at this site. Thus, small molecule inhibitors exploit the differences between protein kinases in their ATP unbound form. Second, it is becoming clear that "holy grail" of selective kinase inhibition is less important and may even be detrimental.

\section{TOFACITINIB}

The restricted receptor expression and phenotype of patients that lack JAK3 has made this kinase an attractive candidate for the development of novel immunosupressants. This has led to both small pharmaceutical start-up companies and established "big pharma" companies developing potent and reasonably selective JAK inhibitors. Two of which, ruxolitinib and tofacitinib are furthest in development.

Tofacitinib (CP-690,550) has high affinity for JAK3 in vitro with an EC50 of $273 \mathrm{nM}$. Although its ability to inhibit JAK3 is highly selective, it is able to partially block JAK1 and to a lesser extent JAK2 with EC50's of 470nM and $6.7 \mathrm{mM}$ respectively [124]. In keeping with these findings, tofacitinib is a potent inhibitor of STAT5 activation by IL-2 stimulation of T lymphoblasts. Through its ability to inhibit JAK1 activity, tofacitinib is able to block the activation of STAT3 and STAT1 downstream of IL-6 and STAT1 but not STAT4 activation downstream of IL-12 even at a high concentration of the inhibitor (500nM in vitro) [125] In summary these changes are associated with a reduction in 
mouse Th1 and Th2 polarization and a reduction in the expression of inflammatory cytokines from both $\mathrm{T}$ cells and cells of the innate immune system [124].

One notable exception to this was the in vitro generation of Th17 cells in mice in the presence of TGF- $\beta$ and IL- 6 [124]. Although tofacitinib is able to inhibit STAT3 phosphorylation downstream of IL-6, critical for the generation of Th17 cells, it is a more potent inhibitor of STAT5 phosphorylation. There is some evidence that these two STAT proteins compete to bind similar enhancer regions within the $I l 17 a-f$ genetic locus and that gene expression is a function of the ratio between STAT3 and STAT5 activity rather than their absolute values [5]. However, in order to be pathogenic, Th17 cells require activation in the presence of IL-23 [126, 127] and through its inhibition of JAK1, tofacitinib is able to block the expression of IL-23 receptor [124]. Thus the ability of tofacitinib to block JAK1 may be an important contributor to the efficacy of the drug.

Tofacitinib has been the subject of clinical investigation as an immunosupresssive agent [128]. The in vivo effect of tofacitinib was first assessed in animal models of organ graft rejection [129]. Tofacitinib was able to suppress both heart or kidney rejection after transplantation and the drug was well tolerated [130]. In cynomolgus monkeys, oral dosing of tofacitinib reduced numbers of NK cells and effector memory $\mathrm{CD}^{+} \mathrm{T}$ cells in a dose dependent manner but preserved $\mathrm{CD}^{+} \mathrm{T}$ cell numbers [131]. The drug has a fourhour half-life and depletion in lymphocyte numbers normalizes soon after cessation of the drug. Lymphocyte depletion and cytokine inhibition both potentially contribute to the prevention of graft rejection and prolongation of kidney allograft survival in cynomolgus monkeys although their relative contributions are uncertain $[132,133]$. Animal models have demonstrated the efficacy of tofacitinib in the treatment of inflammatory disease, both collagen-induced arthritis in mice and adjuvant-induced arthritis in rats could be controlled by JAK3 inhibition. The main immunologic change observed in the tofacitinib treated animals with experimental rheumatoid arthritis compared with controls was a reduction of IL-6 production, a cytokine associated with joint damage [134].

In addition to the inhibition of Th1 polarization via JAK1 inhibition, tofacitinib inhibits Th2 development via its actions on the c $\gamma \mathrm{c}$ cytokine IL-4 [135]. This has lead to the drug being used as a possible therapy for asthma. In a mouse model of Th2-mediated asthma, treatment with tofacitinib inhibited pulmonary eosinophilia. Tofacitinib abrogated IL4-mediated signals and inhibited IL-13, eotaxin, and the eosinophilic influx into the lungs [136].

Tofacitinib has recently been recommended for approval by the FDA for the treatment of rheumatoid arthritis and has completed phase II - III clinical trials for the therapy of inflammatory bowl disease, psoriasis, and the prevention of renal transplant rejection. Preliminary data from first trials are promising, showing efficacy with acceptable toxicity. In a phase II study for rheumatoid arthritis, $70 \%$ to $81 \%$ of patients responded with an ACR20 improvement compared to $29 \%$ in the placebo group. ACR70 was achieved by 13 to $28 \%$ in the tofacitinib treated group, whereas only in $3 \%$ of the patients in the placebo cohort an ACR70 response was observed [137, 138]. Notably, these responses were achieved in patients with rheumatoid arthritis that did not respond to either methotrexate or biologics like tumor necrosis factor antagonists, both regarded as standard of care therapies. Similarly, in psoriasis, a significant and dose-dependent reduction of inflammation and skin plaques was observed as measured by a modified PASI score [139]. Tofacitinib has had success in a phase I trial in prevention of graft rejection in 28 renal transplant patients. Patients were divided into four groups, three of which received doses of $5 \mathrm{mg}$ BID, 15 $\mathrm{mg} \mathrm{BID}$, and $30 \mathrm{mg}$ BID in addition to standard of care immuno-prophylaxis together with a fourth placebo group. No graft loss was reported. At present there are more than a dozen clinical trials underway testing tofacitinib in rheumatoid arthritis, psoriasis, and renal transplantation. The finding that JAK3 deficiency results in severe lymphopenia in mice and humans, suggests that tofacitinib therapy would be associated with a progressive lymphopenia. However, no changes of the major $\mathrm{CD} 4^{+}$or $\mathrm{CD} 8^{+} \mathrm{T}$-lymphocyte subsets have been observed in clinical studies although NK cells are depleted [140].

An important adverse event in the study of renal transplantation was an increased incidence of infections, but in this setting, the patients also received other immunosuppressive drugs. Never the less, the ability of tofacitinib to inhibit JAK1 signaling potentially exposes patients to viral infections. Tofacitinib is as weak inhibitor of JAK2 and a significant reduction of hemoglobin concentration in the low and high dose groups compared to the patients receiving placebo was seen [140]. In this study the anemia was isolated with no other myeloid cell type affected. In contrast, dose-dependent neutropenia was noted in the rheumatoid arthritis study. JAK2 signaling is important for Epo, although the importance of this kinase for granulocyte colony-stimulating factor signaling is less clear [141].

Tofacitinib has also recently been evaluated as a possible candidate for treating adult T-cell leukemia (ATL) and the neurological disorder HTLV-I-associated myelopathy/tropical spastic paraparesis (HAM/TSP) [142]. The underlying pathogenesis of these diseases is a retrovirus HTLV-I-encoded protein tax, which constitutively activates several $c \gamma c$ cytokine function and consequently JAK3/STAT5 signaling pathway. Tofacitinib at $50 \mathrm{nM}$ inhibited STAT5 phosphorylation and spontaneous proliferation of PBMCs from ATL and HAM/TSP patients ex vivo. Tofacitinib was also found to have beneficial effects on survival in an in vivo model of IL-15-transgenic leukaemia. These studies imply that in addition to its immunosuppressive use tofacitinib can become useful for treatment of HTLV-1 associated malignancies.

In addition to tofacitinib, a variety of JAK3 inhibitors have been synthesized, which are at different levels of development (Table 2). These include Rigel (R-348, Phase I), Vertex (VX-509, Phase II), Pharmacopeia/Wyeth (PS608504, preclinical) and Cytopia/Novartis (preclinical).

\section{TARGETING JAK2 IN MPD, RUXOLITINIB AND OTHER INHIBITORS}

Fifteen years ago a groundbreaking study demonstrated that inhibiting JAK2 with AG-490 could improve disease outcome in acute lymphoplastic leukemia [143]. But until 
Table 2. Clinical Trials Involving the Use of Jak Inhibitors

\begin{tabular}{|c|c|c|c|}
\hline \multirow{2}{*}{ Agent } & Principal Targeted Jak(s) & Indication & Development Stage \\
\hline \hline \multirow{2}{*}{ Ruxolitinib } & \multirow{2}{*}{ Jak1, Jak2 } & Myelofibrosis & FDA approved \\
\cline { 3 - 4 } & & Primary polycythemia & Phase III trial \\
\cline { 3 - 4 } & \multirow{2}{*}{ Jak3, Jak1 } & Primary thrombocythemia II trial & FDA approval recommended \\
\hline Tofacitinib & Jak1, Jak2 & Rheumatoid arthritis & Phase II trial \\
\hline Baricitinib & Jak2 & Psoriasis, IBD & Phase II trial \\
\hline CYT387 & Jak1 & Rhase II trial \\
\hline GLPG-0634 & Jak1, Jak2 & Psoriasis & Phase II trial \\
\hline INCB18424 & Jak2 & Myelofibrosis & Phase II trial \\
\hline Lestaurtinib & Jak2 & Myelofibrosis & Phase II trial \\
\hline Pacritinib & Jak3 & Rheumatoid arthritis & Phase II trial \\
\hline VX-509 & Jak3 & Rheumatoid arthritis & Phase II trial \\
\hline R-348 & & Phase I trial & \\
\hline
\end{tabular}

the dramatic discovery that the activating mutations of JAK2 underlie nearly all cases of PPV and many cases of ET and PMF there was little interest in making a kinase inhibitor that was likely to induce a severe pancytopenia [50]. At present, there are at least 15 clinical trials underway using various PTK inhibitors in the setting of MPD.

Ruxolitinib (INCB018424) a JAK1 and JAK2 inhibitor from Incyte was initially tested in patients with either JAK2V617F negative or positive MPD [144]. A total of 153 patients with advanced disease were treated with ruxolitinib for more than one year. The treatment led to $\geq 50 \%$ reduction of splenomegaly in 17 of 33 patients (52\%), which was associated with resolution of constitutional symptoms, improvement of performance status and exercise capacity, and weight gain. Only less than $10 \%$ of the treated patients showed grade 3 or grade 4 adverse events (mainly myelosuppression). Ruxolitinib is now FDA approved for the treatment of PMF and trials are continuing in the treatment of ET and PPV. However it is worth noting that the beneficial effects seen in PMF patients treated with ruxolitinib were observed to be independent of JAK2 mutational status and that there is currently little evidence that ruxolitinib is able to prevent the progression to develop acute myeloid leukemia [144, 145].

In contrast, another orally available JAK2 inhibitor, lestaurtinib (CEP-701) that underwent a phase II clinical study of $22 J A K 2 V 617 F$ positive PMF patients showed less promising results [146]. Lestaurtinib treatment resulted in only modest efficacy, 6 out of 22 patients responded by International Working Group criteria, and no improvement in bone marrow fibrosis or $J A K 2 V 617 F$ allele burden could be observed. Patients also had mild but frequent $(72 \%$ of treated patients) gastrointestinal toxicity.

Several companies have generated putatively selective JAK2 inhibitors, which are being tested in these disorders including AZD1480, S*BIO (SB1518), Exelixis (XL019) and TargeGen (TG101348) [147-149]. The extent to which these compounds are truly JAK2 selective and whether they will be more effective in the treatment of myeloproliferative disease needs to be independently assessed.

It is notable that the Incyte compound Baricitinib (INCB28050) has been reported to inhibit both JAK1 and JAK2 and its ability to inhibit JAK1 in rodent models [150] has led to trials of the drug in rheumatoid arthritis and psoriasis. Moreover, the drug is also being tested in prostate cancer, multiple myeloma, AML, and CML. In addition a second specific JAK1 inhibitor GLPG-0634 (Galapagos) has had success in phase II trials in the treatment of rheumatoid arthritis (Table 2). Efficacy and side effect data from the further study of both these drugs is likely to enhance our understanding into the roles of JAK members in humans.

AZD1480 has been demonstrated to block the TEL-JAK2 fusion protein associated with AML [149] and is being considered for a variety of neoplasia including myeloma and some solid tumors where it has been shown to inhibit downstream STAT3 phosphorylation [151].

Tofacitinib, despite its relatively weaker inhibition of wild type JAK2, has been reported to preferentially inhibit the signaling pathways activated by mutated JAK2 [152]. In vitro, Tofacitinib at concentrations of $1 \mu \mathrm{M}$ induced apoptosis in erythroid progenitor cells of patients with PPV but not from healthy controls [152]. It is unclear whether this drug will have a useful role in MPD compared with the specific inhibitors of JAK2.

\section{SUMMARY}

The last decade has seen a remarkable advances in the field of cytokine biology. New ideas as to the regulation and roles of cytokines in MPD and autoimmune disease in academia have (e.g. discovery of Th17 cells and JAKV617F mutation) co-incited with the development of useful antibody therapies and small molecule inhibitors by pharmaceutical companies.

The generation and investigation of gene targeted mice and the identification of patients with mutations in JAK 
family members has done much to highlight the importance of this kinase family in a range of immune and neoplastic diseases (Table 1). As discussed above, loss-of-function mutations of $J A K 3$ are responsible for a subgroup of SCID patients and a patient with a HIES-like syndrome caused by TYK2 deficiency has been described. Whether we have means to overcome the lack of JAK function in these conditions remains still uncertain. In contrast, gain-offunction mutations of JAK2 and JAK2 fusion proteins that are responsible for a number of lymphoproliferative and myeloproliferative diseases seem more feasible to correct with the new wave of JAK inhibitors that are currently being tested in the clinical trials. In any case the whole scientific and clinical community will likely benefit from the widespread use of JAK inhibitors for these diseases due to the great deal of new information biochemical inhibitor development and preclinical trials have yielded. However, the ultimate goal for both basic and clinical scientist is to cure the patient- not the erratic function of a protein kinase.

\section{ACKNOWLEDGEMENT}

Declared none.

\section{CONFLICT OF INTEREST}

The authors confirm that this article content has no conflicts of interest.

\section{ABBREVIATIONS}

$$
\begin{aligned}
& \mathrm{ACR}=\text { American college of Rheumatology } \\
& \mathrm{AML}=\text { Acute myeloid leukaemia } \\
& \text { ATL }=\text { Adult } \mathrm{T} \text { cell leukaemia } \\
& \mathrm{c} \text { c }=\text { IL-2 receptor common gamma chain } \\
& \mathrm{CML}=\text { Chronic myeloid leukaemia } \\
& \text { ET = Primary thrombocythaemia (Essential } \\
& \text { thrombocythaemia) } \\
& \text { HIES = Hyper IgE syndrome } \\
& \text { HSCT }=\text { Haematopoetic stem cell transplant } \\
& \mathrm{HTLV}=\text { Human } \mathrm{T} \text { cell leukaemia virus } \\
& \text { IFN }=\text { Interfearon } \\
& \text { IL }=\text { Interleukin } \\
& \mathrm{JAK}=\text { Janus Kinase } \\
& \text { MPD = Myeloproliferative disease } \\
& \text { PMF = Primary myelofibrosis } \\
& \text { PPV = Primary polycythaemia (Polycythaemia rubra } \\
& \text { vera) } \\
& \text { PTK = Protein tyrosine kinase } \\
& \text { SCID = Severe combined immuno-deficiency } \\
& \text { SOCS }=\text { Supressor of cytokine signaling } \\
& \text { STAT }=\text { Signal transducer and activator of transcription } \\
& \text { TYK = Tyrosine kinase }
\end{aligned}
$$

\section{REFERENCES}

[1] Riedy MC, Dutra AS, Blake TB, et al. Genomic sequence, organization, and chromosomal localization of human JAK3. Genomics 1996; 37: 57-61.

[2] Firmbach-Kraft I, Byers M, Shows T, Dalla-Favera R, Krolewski JJ. tyk2, prototype of a novel class of non-receptor tyrosine kinase genes. Oncogene 1990; 5: 1329-36.

[3] Darnell JE Jr, Kerr IM, Stark GR. Jak-STAT pathways and transcriptional activation in response to IFNs and other extracellular signaling proteins. Science 1994; 264: 1415-21.

[4] Decker T, Kovarik P. Serine phosphorylation of STATs. Oncogene 2000; 19: 2628-37.

[5] Yang XP, Ghoreschi K, Steward-Tharp SM, et al. Opposing regulation of the locus encoding IL-17 through direct, reciprocal actions of STAT3 and STAT5. Nat Immunol 2011; 12: 247-54.

[6] Wei L, Vahedi G, Sun HW, et al. Discrete roles of STAT4 and STAT6 transcription factors in tuning epigenetic modifications and transcription during $\mathrm{T}$ helper cell differentiation. Immunity 2010; 32: 840-51.

[7] Yamaoka K, Saharinen P, Pesu M, Holt VE 3rd, Silvennoinen O, O'Shea JJ. The Janus kinases (Jaks). Genome Biol 2004; 5: 253.

[8] Pesu M, O'Shea J, Hennighausen L, Silvennoinen O. Identification of an acquired mutation in Jak2 provides molecular insights into the pathogenesis of myeloproliferative disorders. Mol Interv 2005; 5: 211-5.

[9] Tefferi A, Sirhan S, Lasho TL, et al. Concomitant neutrophil JAK2 mutation screening and PRV-1 expression analysis in myeloproliferative disorders and secondary polycythaemia. $\mathrm{Br} \mathrm{J}$ Haematol 2005; 131: 166-71.

[10] Kralovics R, Teo SS, Buser AS, et al. Altered gene expression in myeloproliferative disorders correlates with activation of signaling by the V617F mutation of Jak2. Blood 2005; 106: 3374-6.

[11] Lupardus PJ, Skiniotis G, Rice AJ, et al. Structural snapshots of full-length Jak1, a transmembrane gp130/IL-6/IL-6Ralpha cytokine receptor complex, and the receptor-Jak1 holocomplex. Structure 2011; 19: 45-55.

[12] Zhou YJ, Chen M, Cusack NA, et al. Unexpected effects of FERM domain mutations on catalytic activity of Jak3: structural implication for Janus kinases. Mol Cell 2001; 8: 959-69.

[13] Haan S, Margue C, Engrand A, et al. Dual role of the Jak1 FERM and kinase domains in cytokine receptor binding and in stimulation-dependent Jak activation. J Immunol 2008; 180: 9981007.

[14] Boggon TJ, Li Y, Manley PW, Eck MJ. Crystal structure of the Jak3 kinase domain in complex with a staurosporine analog. Blood 2005; 106: 996-1002.

[15] Thoma G, Nuninger F, Falchetto R, et al. Identification of a potent janus kinase 3 inhibitor with high selectivity within the janus kinase family. J Med Chem 2011; 54(1): 284-8.

[16] Williams NK, Bamert RS, Patel O, et al. Dissecting specificity in the Janus kinases: the structures of JAK-specific inhibitors complexed to the JAK1 and JAK2 protein tyrosine kinase domains. J Mol Biol 2009; 387: 219-32.

[17] Lucet IS, Fantino E, Styles M, et al. The structural basis of Janus kinase 2 inhibition by a potent and specific pan-Janus kinase inhibitor. Blood 2006; 107: 176-83.

[18] Yasukawa H, Misawa H, Sakamoto H, et al. The JAK-binding protein JAB inhibits Janus tyrosine kinase activity through binding in the activation loop. EMBO J 1999; 18: 1309-20.

[19] Neubauer H, Cumano A, Muller M, Wu H, Huffstadt U, Pfeffer K. Jak2 deficiency defines an essential developmental checkpoint in definitive hematopoiesis. Cell 1998; 93: 397-409.

[20] Argetsinger LS, Kouadio JL, Steen H, Stensballe A, Jensen ON, Carter-Su C. Autophosphorylation of JAK2 on tyrosines 221 and 570 regulates its activity. Mol Cell Biol 2004; 24: 4955-67.

[21] Feener EP, Rosario F, Dunn SL, Stancheva Z, Myers MG Jr. Tyrosine phosphorylation of Jak2 in the $\mathrm{JH} 2$ domain inhibits cytokine signaling. Mol Cell Biol 2004; 24: 4968-78.

[22] Robertson SA, Koleva RI, Argetsinger LS, et al. Regulation of Jak2 function by phosphorylation of Tyr317 and Tyr637 during cytokine signaling. Mol Cell Biol 2009; 29: 3367-78. 
[23] Mazurkiewicz-Munoz AM, Argetsinger LS, Kouadio JL, et al. Phosphorylation of JAK2 at serine 523: a negative regulator of JAK2 that is stimulated by growth hormone and epidermal growth factor. Mol Cell Biol 2006; 26: 4052-62.

[24] Ishida-Takahashi R, Rosario F, Gong Y, et al. Phosphorylation of Jak2 on Ser(523) inhibits Jak2-dependent leptin receptor signaling. Mol Cell Biol 2006; 26: 4063-73.

[25] Karaghiosoff M, Neubauer H, Lassnig C, et al. Partial impairment of cytokine responses in Tyk2-deficient mice. Immunity 2000; 13: 549-60.

[26] Shimoda K, Kato K, Aoki K, et al. Tyk2 plays a restricted role in IFN alpha signaling, although it is required for IL-12-mediated T cell function. Immunity $2000 ; 13: 561-71$.

[27] Saharinen P, Takaluoma K, Silvennoinen O. Regulation of the Jak2 tyrosine kinase by its pseudokinase domain. Mol Cell Biol 2000; 20: 3387-95.

[28] Hanratty WP, Dearolf CR. The Drosophila Tumorous-lethal hematopoietic oncogene is a dominant mutation in the hopscotch locus. Mol Gen Genet 1993; 238: 33-7.

[29] Zhao R, Xing S, Li Z, et al. Identification of an acquired JAK2 mutation in polycythemia vera. J Biol Chem 2005; 280: 22788-92.

[30] Minegishi Y, Saito M, Morio T, et al. Human tyrosine kinase 2 deficiency reveals its requisite roles in multiple cytokine signals involved in innate and acquired immunity. Immunity 2006; 25 : $745-55$.

[31] Szabo SJ, Sullivan BM, Peng SL, Glimcher LH. Molecular mechanisms regulating Th1 immune responses. Annu Rev Immunol 2003; 21: 713-58

[32] Seto Y, Nakajima H, Suto A, et al. Enhanced Th2 cell-mediated allergic inflammation in Tyk2-deficient mice. J Immunol 2003; 170: $1077-83$

[33] Murphy CA, Langrish CL, Chen Y, et al. Divergent pro- and antiinflammatory roles for IL-23 and IL-12 in joint autoimmune inflammation. J Exp Med 2003; 198: 1951-7.

[34] Cua DJ, Sherlock J, Chen Y, et al. Interleukin-23 rather than interleukin-12 is the critical cytokine for autoimmune inflammation of the brain. Nature 2003; 421: 744-8.

[35] Chen Y, Langrish CL, McKenzie B, et al. Anti-IL-23 therapy inhibits multiple inflammatory pathways and ameliorates autoimmune encephalomyelitis. J Clin Invest 2006; 116: 1317-26.

[36] McKenzie BS, Kastelein RA, Cua DJ. Understanding the IL-23-IL17 immune pathway. Trends Immunol 2006; 27: 17-23.

[37] Zheng Y, Valdez PA, Danilenko DM, et al. IL-22 is indispensable in early host defense against attaching and effacing bacterial pathogens. Nat Med 2008; 14: 282-9.

[38] Lees CW, Barrett JC, Parkes M, Satsangi J. New IBD genetics: common pathways with other diseases. Gut 2011; 60(12): 1739-53.

[39] Watford WT, O'Shea JJ. Human tyk2 kinase deficiency: another primary immunodeficiency syndrome. Immunity 2006; 25: 695-7.

[40] Rodig SJ, Meraz MA, White JM, et al. Disruption of the Jak1 gene demonstrates obligatory and nonredundant roles of the Jaks in cytokine-induced biologic responses. Cell 1998; 93: 373-83.

[41] Muller M, Briscoe J, Laxton C, et al. The protein tyrosine kinase JAK1 complements defects in interferon-alpha/beta and -gamma signal transduction. Nature 1993; 366: 129-35.

[42] Rochman Y, Kashyap M, Robinson GW, et al. Thymic stromal lymphopoietin-mediated STAT5 phosphorylation via kinases JAK1 and JAK2 reveals a key difference from IL-7-induced signaling. Proc Natl Acad Sci USA 2010; 107: 19455-60.

[43] Haan C, Rolvering C, Raulf F, et al. Jak1 Has a Dominant Role over Jak3 in Signal Transduction through gammac-Containing Cytokine Receptors. Chem Biol 2011; 18: 314-23.

[44] Wartman LD, Larson DE, Xiang Z, et al. Sequencing a mouse acute promyelocytic leukemia genome reveals genetic events relevant for disease progression. J Clin Invest 2011; 121: 1445-55.

[45] Flex E, Petrangeli V, Stella L, et al. Somatically acquired JAK1 mutations in adult acute lymphoblastic leukemia. J Exp Med 2008; 205: 751-8.

[46] Harvey RC, Mullighan CG, Chen IM, et al. Rearrangement of CRLF2 is associated with mutation of JAK kinases, alteration of IKZF1, Hispanic/Latino ethnicity, and a poor outcome in pediatric B-progenitor acute lymphoblastic leukemia. Blood 2010; 115: 5312-21.

[47] Asnafi V, Le Noir S, Lhermitte L, et al. JAK1 mutations are not frequent events in adult T-ALL: a GRAALL study. Br J Haematol 2010; 148: 178-9
[48] Hornakova T, Chiaretti S, Lemaire MM, et al. ALL-associated JAK1 mutations confer hypersensitivity to the antiproliferative effect of type I interferon. Blood 2010; 115: 3287-95.

[49] Witthuhn BA, Quelle FW, Silvennoinen O, et al. JAK2 associates with the erythropoietin receptor and is tyrosine phosphorylated and activated following stimulation with erythropoietin. Cell 1993; 74: 227-36

[50] James C, Ugo V, Le Couedic JP, et al. A unique clonal JAK2 mutation leading to constitutive signalling causes polycythaemia vera. Nature 2005; 434: 1144-8

[51] Kralovics R, Passamonti F, Buser AS, et al. A gain-of-function mutation of JAK2 in myeloproliferative disorders. N Eng1 J Med 2005; 352: 1779-90.

[52] Baxter EJ, Scott LM, Campbell PJ, et al. Acquired mutation of the tyrosine kinase JAK2 in human myeloproliferative disorders. Lancet 2005; 365: 1054-61.

[53] Levine RL, Wadleigh M, Cools J, et al. Activating mutation in the tyrosine kinase JAK2 in polycythemia vera, essentia thrombocythemia, and myeloid metaplasia with myelofibrosis. Cancer Cell 2005; 7: 387-97.

[54] Nowell PC. Discovery of the Philadelphia chromosome: a personal perspective. J Clin Invest 2007; 117: 2033-5.

[55] Druker BJ. Perspectives on the development of a molecularly targeted agent. Cancer Cell 2002; 1: 31-6.

[56] Hookham MB, Elliott J, Suessmuth Y, et al. The myeloproliferative disorder-associated JAK2 V617F mutant escapes negative regulation by suppressor of cytokine signaling 3. Blood 2007; 109: 4924-9.

[57] Lacronique V, Boureux A, Valle VD, et al. A TEL-JAK2 fusion protein with constitutive kinase activity in human leukemia. Science 1997; 278: 1309-12.

[58] Carron C, Cormier F, Janin A, et al. TEL-JAK2 transgenic mice develop T-cell leukemia. Blood 2000; 95: 3891-9.

[59] Kennedy JA, Barabe F, Patterson BJ, et al. Expression of TELJAK2 in primary human hematopoietic cells drives erythropoietinindependent erythropoiesis and induces myelofibrosis in vivo. Proc Natl Acad Sci USA 2006; 103: 16930-5.

[60] Reiter A, Walz C, Watmore A, et al. The $\mathrm{t}(8 ; 9)(\mathrm{p} 22 ; \mathrm{p} 24)$ is a recurrent abnormality in chronic and acute leukemia that fuses PCM1 to JAK2. Cancer Res 2005; 65: 2662-7.

[61] Bousquet M, Quelen C, De Mas V, et al. The t(8; 9)(p22; p24) translocation in atypical chronic myeloid leukaemia yields a new PCM1-JAK2 fusion gene. Oncogene 2005; 24: 7248-52.

[62] Griesinger F, Hennig H, Hillmer F, et al. A BCR-JAK2 fusion gene as the result of a $\mathrm{t}(9 ; 22)(\mathrm{p} 24 ; \mathrm{q} 11.2)$ translocation in a patient with a clinically typical chronic myeloid leukemia. Genes Chrom Cancer 2005; 44: 329-33.

[63] Cirmena G, Aliano S, Fugazza G, et al. A BCR-JAK2 fusion gene as the result of a $\mathrm{t}(9 ; 22)(\mathrm{p} 24 ; \mathrm{q} 11)$ in a patient with acute myeloid leukemia. Cancer Genet Cytogenet 2008; 183: 105-8.

[64] Golub TR, Barker GF, Lovett M, Gilliland DG. Fusion of PDGF receptor beta to a novel ets-like gene, tel, in chronic myelomonocytic leukemia with $\mathrm{t}(5 ; 12)$ chromosomal translocation. Cell 1994; 77: 307-16.

[65] Janssen JW, Ridge SA, Papadopoulos P, et al. The fusion of TEL and $\mathrm{ABL}$ in human acute lymphoblastic leukaemia is a rare event Br J Haematol 1995; 90: 222-4.

[66] Gaikwad A, Rye CL, Devidas M, et al. Prevalence and clinical correlates of JAK2 mutations in Down syndrome acute lymphoblastic leukaemia. Br J Haematol 2009; 144: 930-2.

[67] Kearney L, Gonzalez De CD, Yeung J, et al. Specific JAK2 mutation (JAK2R683) and multiple gene deletions in Down syndrome acute lymphoblastic leukemia. Blood 2009; 113: 646-8.

[68] Bercovich D, Ganmore I, Scott LM, et al. Mutations of JAK2 in acute lymphoblastic leukaemias associated with Down's syndrome. Lancet 2008; 372: 1484-92.

[69] Mullighan CG, Zhang J, Harvey RC, et al. JAK mutations in highrisk childhood acute lymphoblastic leukemia. Proc Natl Acad Sci USA 2009; 106: 9414-8

[70] Mullighan CG, Collins-Underwood JR, Phillips LA, et al. Rearrangement of CRLF2 in B-progenitor- and Down syndromeassociated acute lymphoblastic leukemia. Nat Genet 2009; 41 1243-6.

[71] Hertzberg L, Vendramini E, Ganmore I, et al. Down syndrome acute lymphoblastic leukemia, a highly heterogeneous disease in which aberrant expression of CRLF2 is associated with mutated 
JAK2: a report from the International BFM Study Group. Blood 2010; 115: 1006-17.

[72] Spiekermann K, Pau M, Schwab R, Schmieja K, Franzrahe S, Hiddemann W. Constitutive activation of STAT3 and STAT5 is induced by leukemic fusion proteins with protein tyrosine kinase activity and is sufficient for transformation of hematopoietic precursor cells. Exp Hematol 2002; 30: 262-71.

[73] Rottapel R, Ilangumaran S, Neale C, et al. The tumor suppressor activity of SOCS-1. Oncogene 2002; 21: 4351-62.

[74] Kamizono S, Hanada T, Yasukawa H, et al. The SOCS box of SOCS-1 accelerates ubiquitin-dependent proteolysis of TEL-JAK2. J Biol Chem 2001; 276: 12530-8.

[75] Frantsve J, Schwaller J, Sternberg DW, Kutok J, Gilliland DG. Socs-1 inhibits TEL-JAK2-mediated transformation of hematopoietic cells through inhibition of JAK2 kinase activity and induction of proteasome-mediated degradation. Mol Cell Biol 2001; 21: 3547-57.

[76] Dawson MA, Bannister AJ, Gottgens B, et al. JAK2 phosphorylates histone H3Y41 and excludes HP1alpha from chromatin. Nature 2009; 461: 819-22.

[77] Rui L, Emre NC, Kruhlak MJ, et al. Cooperative epigenetic modulation by cancer amplicon genes. Cancer Cell 2010; 18: 590605 .

[78] Rochman Y, Spolski R, Leonard WJ. New insights into the regulation of $\mathrm{T}$ cells by gamma(c) family cytokines. Nat Rev Immunol 2009; 9: 480-90.

[79] Noguchi M, Yi H, Rosenblatt HM, et al. Interleukin-2 receptor gamma chain mutation results in $\mathrm{X}$-linked severe combined immunodeficiency in humans. Cell 1993; 73: 147-57.

[80] Russell SM, Tayebi N, Nakajima H, et al. Mutation of Jak3 in a patient with SCID: essential role of Jak3 in lymphoid development. Science 1995; 270: 797-800.

[81] Yao Z, Cui Y, Watford WT, et al. Stat5a/b are essential for normal lymphoid development and differentiation. Proc Natl Acad Sci USA 2006; 103: 1000-5.

[82] Nutt SL, Urbanek P, Rolink A, Busslinger M. Essential functions of Pax5 (BSAP) in pro-B cell development: difference between fetal and adult $B$ lymphopoiesis and reduced V-to-DJ recombination at the IgH locus. Genes Dev 1997; 11: 476-91.

[83] Puel A, Ziegler SF, Buckley RH, Leonard WJ. Defective IL7R expression in $\mathrm{T}(-) \mathrm{B}(+) \mathrm{NK}(+)$ severe combined immunodeficiency. Nat Genet 1998; 20: 394-7.

[84] Schorle H, Holtschke T, Hunig T, Schimpl A, Horak I. Development and function of T cells in mice rendered interleukin-2 deficient by gene targeting. Nature 1991; 352: 621-4.

[85] Kundig TM, Schorle H, Bachmann MF, Hengartner H, Zinkernagel RM, Horak I. Immune responses in interleukin-2-deficient mice. Science 1993; 262: 1059-61.

[86] Nelson BH. Interleukin-2 signaling and the maintenance of selftolerance. Curr Dir Autoimmun 2002; 5: 92-112.

[87] Shevach EM. From vanilla to 28 flavors: multiple varieties of $\mathrm{T}$ regulatory cells. Immunity 2006; 25: 195-201.

[88] Sharfe N, Dadi HK, Shahar M, Roifman CM. Human immune disorder arising from mutation of the alpha chain of the interleukin2 receptor. Proc Natl Acad Sci USA 1997; 94: 3168-71.

[89] Roifman CM. Human IL-2 receptor alpha chain deficiency. Pediatr Res 2000; 48: 6-11.

[90] Lohr J, Knoechel B, Wang JJ, Villarino AV, Abbas AK. Role of IL-17 and regulatory $\mathrm{T}$ lymphocytes in a systemic autoimmune disease. J Exp Med 2006; 203: 2785-91.

[91] Laurence A, Tato CM, Davidson TS, et al. Interleukin-2 signaling via STAT5 constrains T helper 17 cell generation. Immunity 2007; 26: 371-81.

[92] Bettelli E, Carrier Y, Gao W, et al. Reciprocal developmental pathways for the generation of pathogenic effector TH17 and regulatory T cells. Nature 2006; 441: 235-8.

[93] Veldhoen M, Hocking RJ, Atkins CJ, Locksley RM, Stockinger B. TGFbeta in the context of an inflammatory cytokine milieu supports de novo differentiation of IL-17-producing $\mathrm{T}$ cells. Immunity 2006; 24: 179-89.

[94] Chen W, Jin W, Hardegen N, et al. Conversion of peripheral CD4+CD25- naive $\mathrm{T}$ cells to $\mathrm{CD} 4+\mathrm{CD} 25+$ regulatory $\mathrm{T}$ cells by TGF-beta induction of transcription factor Foxp3. J Exp Med 2003; 198: 1875-86.

[95] Yao Z, Kanno Y, Kerenyi M, et al. Nonredundant roles for Stat5a/b in directly regulating Foxp3. Blood 2007; 109: 4368-75.
[96] Mathur AN, Chang HC, Zisoulis DG, et al. Stat3 and Stat4 direct development of IL-17-secreting Th cells. J Immunol 2007; 178: 4901-7.

[97] Yang XO, Panopoulos AD, Nurieva R, et al. STAT3 regulates cytokine-mediated generation of inflammatory helper $\mathrm{T}$ cells. $\mathrm{J}$ Biol Chem 2007; 282: 9358-63.

[98] Chen Z, Laurence A, Kanno Y, et al. Selective regulatory function of Socs 3 in the formation of IL-17-secreting T cells. Proc Natl Acad Sci USA 2006; 103: 8137-42.

[99] Sharfe N, Shahar M, Roifman CM. An interleukin-2 receptor gamma chain mutation with normal thymus morphology. J Clin Invest 1997; 100: 3036-43.

[100] Frucht DM, Gadina M, Jagadeesh GJ, et al. Unexpected and variable phenotypes in a family with JAK3 deficiency. Genes Immun 2001; 2: 422-32.

[101] Mella P, Imberti L, Brugnoni D, et al. Development of autologous $\mathrm{T}$ lymphocytes in two males with X-linked severe combined immune deficiency: molecular and cellular characterization. Clin Immunol 2000; 95: 39-50.

[102] Brugnoni D, Notarangelo LD, Sottini A, et al. Development of autologous, oligoclonal, poorly functioning $\mathrm{T}$ lymphocytes in a patient with autosomal recessive severe combined immunodeficiency caused by defects of the Jak3 tyrosine kinase. Blood 1998; 91: 949-55.

[103] Spolski R, Leonard WJ. IL-21 and T follicular helper cells. Int Immunol 2010; 22: 7-12.

[104] Hacein-Bey-Abina S, Le Deist F, Carlier F, et al. Sustained correction of X-linked severe combined immunodeficiency by ex vivo gene therapy. N Engl J Med 2002; 346: 1185-93.

[105] Hacein-Bey-Abina S, Von Kalle C, Schmidt M, et al. LMO2associated clonal $\mathrm{T}$ cell proliferation in two patients after gene therapy for SCID-X1. Science 2003; 302: 415-9.

[106] Woods NB, Bottero V, Schmidt M, von Kalle C, Verma IM. Gene therapy: therapeutic gene causing lymphoma. Nature 2006; 440: 1123.

[107] Almarza E, Zhang F, Santilli G, et al. Correction of SCID-X1 using an enhancerless Vav promoter. Hum Gene Ther 2011; 22: 263-70.

[108] Birkenkamp KU, Geugien M, Lemmink HH, Kruijer W, Vellenga E. Regulation of constitutive STAT5 phosphorylation in acute myeloid leukemia blasts. Leukemia 2001; 15: 1923-31.

[109] Tyner JW, Walters DK, Willis SG, et al. RNAi screening of the tyrosine kinome identifies therapeutic targets in acute myeloid leukemia. Blood 2008; 111: 2238-45.

[110] Malinge S, Ragu C, Della-Valle V, et al. Activating mutations in human acute megakaryoblastic leukemia. Blood 2008; 112: 4220-6.

[111] Walters DK, Mercher T, Gu TL, O'Hare T, Tyner JW, Loriaux M, et al. Activating alleles of JAK3 in acute megakaryoblastic leukemia. Cancer Cell 2006; 10: 65-75.

[112] Malamut G, El Machhour R, Montcuquet N, et al. IL-15 triggers an antiapoptotic pathway in human intraepithelial lymphocytes that is a potential new target in celiac disease-associated inflammation and lymphomagenesis. J Clin Invest 2010; 120: 2131-43.

[113] Dien Bard J, Gelebart P, Anand M, et al. IL-21 contributes to JAK3/STAT3 activation and promotes cell growth in ALK-positive anaplastic large cell lymphoma. Am J Pathol 2009; 175: 825-34.

[114] Nosaka T, van Deursen JM, Tripp RA, et al. Defective lymphoid development in mice lacking Jak3. Science 1995; 270: 800-2.

[115] Park SY, Saijo K, Takahashi T, et al. Developmental defects of lymphoid cells in Jak3 kinase-deficient mice. Immunity 1995; 3: 771-82.

[116] Thomis DC, Gurniak CB, Tivol E, Sharpe AH, Berg LJ. Defects in $\mathrm{B}$ lymphocyte maturation and $\mathrm{T}$ lymphocyte activation in mice lacking Jak3. Science 1995; 270: 794-7.

[117] Ungureanu D, Saharinen P, Junttila I, Hilton DJ, Silvennoinen O. Regulation of Jak2 through the ubiquitin-proteasome pathway involves phosphorylation of Jak2 on Y1007 and interaction with SOCS-1. Mol Cell Biol 2002; 22: 3316-26.

[118] Bersenev A, Wu C, Balcerek J, et al. Lnk constrains myeloproliferative diseases in mice. J Clin Invest 2010; 120: 205869.

[119] Oh ST, Simonds EF, Jones C, et al. Novel mutations in the inhibitory adaptor protein LNK drive JAK-STAT signaling in patients with myeloproliferative neoplasms. Blood 2010; 116: 98892.

[120] Betz A, Darnell JE, Jr. A Hopscotch-chromatin connection. Nat Genet 2006; 38: 977-9. 
[121] Shi S, Calhoun HC, Xia F, Li J, Le L, Li WX. JAK signaling globally counteracts heterochromatic gene silencing. Nat Genet 2006; 38: 1071-6.

[122] Girodon F, Steinkamp MP, Cleyrat C, Hermouet S, Wilson BS. Confocal imaging studies cast doubt on nuclear localization of JAK2V617F. Blood 2011; 118: 2633-4

[123] Jakel H, Weinl C, Hengst L. Phosphorylation of p27Kip1 by JAK2 directly links cytokine receptor signaling to cell cycle control. Oncogene 2011;30(32): 3502-12.

[124] Ghoreschi K, Jesson MI, Li X, et al. Modulation of Innate and Adaptive Immune Responses by Tofacitinib (CP-690,550). J Immunol 2011; 186: 4234-43.

[125] Jiang JK, Ghoreschi K, Deflorian F, et al. Examining the chirality, conformation and selective kinase inhibition of 3-((3R,4R)-4-methyl-3(methyl(7H-pyrrolo[2,3-d]pyrimidin-4-yl)amino)piperidin-1-yl)-3-oxopropanenitrile (CP-690,550). J Med Chem 2008; 51: 8012-8.

[126] Ghoreschi K, Laurence A, Yang XP, et al. Generation of pathogenic $\mathrm{T}(\mathrm{H}) 17$ cells in the absence of TGF-beta signalling. Nature 2010; 467: 967-71.

[127] McGeachy MJ, Chen Y, Tato CM, et al. The interleukin 23 receptor is essential for the terminal differentiation of interleukin 17-producing effector T helper cells in vivo. Nat Immunol 2009; 10: 314-24.

[128] Ghoreschi K, Laurence A, O'Shea JJ. Janus kinases in immune cell signaling. Immunol Rev 2009; 228: 273-87.

[129] Kudlacz E, Perry B, Sawyer P, et al. The novel JAK-3 inhibitor $\mathrm{CP}-690550$ is a potent immunosuppressive agent in various murine models. Am J Transplant 2004; 4: 51-7.

[130] Changelian PS, Flanagan ME, Ball DJ, et al. Prevention of organ allograft rejection by a specific Janus kinase 3 inhibitor. Science 2003; 302: $875-8$

[131] Conklyn M, Andresen C, Changelian P, Kudlacz E. The JAK3 inhibitor CP-690550 selectively reduces $\mathrm{NK}$ and $\mathrm{CD} 8+$ cell numbers in cynomolgus monkey blood following chronic oral dosing. J Leukoc Biol 2004; 76: 1248-55.

[132] Borie DC, Changelian PS, Larson MJ, et al. Immunosuppression by the JAK3 inhibitor CP-690,550 delays rejection and significantly prolongs kidney allograft survival in nonhuman primates. Transplantation 2005; 79: 791-801.

[133] Paniagua R, Si MS, Flores MG, et al. Effects of JAK3 inhibition with CP-690,550 on immune cell populations and their functions in nonhuman primate recipients of kidney allografts. Transplantation 2005; 80: 1283-92.

[134] Milici AJ, Kudlacz EM, Audoly L, Zwillich S, Changelian P. Cartilage preservation by inhibition of Janus kinase 3 in two rodent models of rheumatoid arthritis. Arthritis Res Ther 2008; 10: R14.

[135] Paul WE, Zhu J. How are T(H)2-type immune responses initiated and amplified? Nat Rev Immunol 2010; 10: 225-35.

[136] Kudlacz E, Conklyn M, Andresen C, Whitney-Pickett C, Changelian P. The JAK-3 inhibitor CP-690550 is a potent antiinflammatory agent in a murine model of pulmonary eosinophilia. Eur J Pharmacol 2008; 582: 154-61.

[137] Coombs JH, Bloom BJ, Breedveld FC, et al. Improved pain, physical functioning and health status in patients with rheumatoid arthritis treated with CP-690,550, an orally active Janus kinase (JAK) inhibitor: results from a randomised, double-blind, placebocontrolled trial. Ann Rheum Dis 2010; 69: 413-6.
[138] Kremer JM, Bloom BJ, Breedveld FC, et al. The safety and efficacy of a JAK inhibitor in patients with active rheumatoid arthritis: Results of a double-blind, placebo-controlled phase IIa trial of three dosage levels of CP-690,550 versus placebo. Arthritis Rheum 2009; 60: 1895-905.

[139] Boy MG, Wang C, Wilkinson BE, et al. Double-blind, placebocontrolled, dose-escalation study to evaluate the pharmacologic effect of CP-690,550 in patients with psoriasis. J Invest Dermatol 2009; 129: 2299-302.

[140] van Gurp E, Weimar W, Gaston R, et al. Phase 1 dose-escalation study of CP-690 550 in stable renal allograft recipients: preliminary findings of safety, tolerability, effects on lymphocyte subsets and pharmacokinetics. Am J Transplant 2008; 8: 1711-8.

[141] Parganas E, Wang D, Stravopodis D, et al. Jak2 is essential for signaling through a variety of cytokine receptors. Cell 1998; 93 : 385-95.

[142] Ju W, Zhang M, Jiang JK, et al. CP-690,550, a therapeutic agent, inhibits cytokine-mediated Jak3 activation and proliferation of $\mathrm{T}$ cells from patients with ATL and HAM/TSP. Blood 2011; 117: 1938-46.

[143] Meydan N, Grunberger T, Dadi H, et al. Inhibition of acute lymphoblastic leukaemia by a Jak-2 inhibitor. Nature 1996; 379 : 645-8.

[144] Verstovsek S, Kantarjian H, Mesa RA, et al. Safety and efficacy of INCB018424, a JAK1 and JAK2 inhibitor, in myelofibrosis. N Engl J Med 2010; 363: 1117-27.

[145] Harrison C, Kiladjian JJ, Al-Ali HK, et al. JAK inhibition with ruxolitinib versus best available therapy for myelofibrosis. N Engl J Med 2012; 366: 787-98.

[146] Santos FP, Kantarjian HM, Jain N, et al. Phase 2 study of CEP701 , an orally available JAK2 inhibitor, in patients with primary or post-polycythemia vera/essential thrombocythemia myelofibrosis. Blood 2010; 115: 1131-6.

[147] Wernig G, Kharas MG, Okabe R, et al. Efficacy of TG101348, a selective JAK2 inhibitor, in treatment of a murine model of JAK2V617F-induced polycythemia vera. Cancer Cell 2008; 13: 311-20.

[148] Geron I, Abrahamsson AE, Barroga CF, et al. Selective inhibition of JAK2-driven erythroid differentiation of polycythemia vera progenitors. Cancer Cell 2008; 13: 321-30.

[149] Ioannidis S, Lamb ML, Wang T, et al. Discovery of 5-Chloro$\mathrm{N}(2)-[(1 \mathrm{~S})-1$-(5-fluoropyrimidin-2-yl)ethyl]-N(4)-(5-methyl-1Hpyrazol-3-yl)pyrimidine-2,4-diamine (AZD1480) as a Novel Inhibitor of the Jak/Stat Pathway. J Med Chem 2011; 54(1): 26276.

[150] Fridman JS, Scherle PA, Collins R, et al. Selective inhibition of JAK1 and JAK2 is efficacious in rodent models of arthritis: preclinical characterization of INCB028050. J Immunol 2010; 184: 5298-307.

[151] Hedvat M, Huszar D, Herrmann A, et al. The JAK2 inhibitor AZD1480 potently blocks Stat3 signaling and oncogenesis in solid tumors. Cancer Cell 2009; 16: 487-97.

[152] Manshouri T, Quintas-Cardama A, Nussenzveig RH, et al. The JAK kinase inhibitor CP-690,550 suppresses the growth of human polycythemia vera cells carrying the JAK2V617F mutation. Cancer Sci 2008; 99: 1265-73

(C) Laurence et al.; Licensee Bentham Open.

This is an open access article licensed under the terms of the Creative Commons Attribution Non-Commercial License (http:/creativecommons.org/licenses/by-nc/ $3.0 /$ ) which permits unrestricted, non-commercial use, distribution and reproduction in any medium, provided the work is properly cited. 